\title{
Nickel hydroxide electrodeposition from nickel nitrate solutions: mechanistic studies
}

\author{
R.S. Jayashree*, P. Vishnu Kamath \\ Department of Chemistry, Central College, Bangalore University, Bangalore 560001, India
}

Received 28 April 2000; received in revised form 13 July 2000; accepted 22 August 2000

\begin{abstract}
Nickel hydroxide electrodeposition by cathodic reduction of nitrate ions follows an EC (electrochemical reaction followed by an irreversible chemical reaction) mechanism. On subsequent cycling, the electrodeposited nickel hydroxide undergoes a reversible redox reaction. (C) 2001 Elsevier Science B.V. All rights reserved.
\end{abstract}

Keywords: Nickel hydroxide; Cyclic voltammetry; Nitrate bath

\section{Introduction}

Nickel hydroxide is the positive electrode material of all nickel-based alkaline secondary cells such as the $\mathrm{Ni}-\mathrm{Cd}$, Ni$\mathrm{Fe}, \mathrm{Ni}-\mathrm{Zn}$ and $\mathrm{Ni}-\mathrm{MH}$ (metal hydride). There is, therefore, considerable interest in the science and technology of highperformance nickel hydroxide electrodes.

There are two important problems in the preparation of nickel hydroxide electrodes.

1. Nickel hydroxide crystallizes in two polymorphic modifications, namely, $\alpha$ and $\beta$ [1]. The $\alpha$-phase exchanges $1.7 \mathrm{e}$ per $\mathrm{Ni}$ atom during reversible cycling [2] but the $\beta$-phase exchanges only $1 \mathrm{e}$ per $\mathrm{Ni}$ atom. The $\alpha$-phase is thermodynamically unstable, however, and rapidly ages to the $\beta$-form. Accordingly, the superior properties of $\alpha$-nickel hydroxide have not been realized in the operational conditions of a battery [3]. The development of reliable routes to the synthesis and stabilization of $\alpha$-nickel hydroxide [4-6] is a major scientific challenge.

2. Nickel hydroxide is a semiconductor and has to be bonded to a suitable porous conducting support, for the purpose of electrode fabrication. The development of light-weight supports and appropriate methods of bonding the support to the active material is a problem of technology [7].

The positive electrodes of all nickel-based alkaline secondary cells are prepared by the electrodeposition of nickel

\footnotetext{
${ }^{*}$ Corresponding author. Tel.: +91-80-22-11-679.

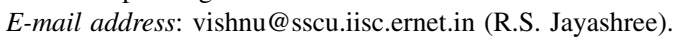

hydroxide in sintered nickel porous plaques [8-10]. By suitable choice of parameters which control the electrodeposition, $\alpha$-nickel hydroxide can be selectively synthesized in preference to the $\beta$-form [4]. Further, electrochemical deposition of nickel hydroxide in sintered nickel porous plaques provides the best bonding and highest material utilization among all the electrode fabrication methods which are presently employed [7]. Electrodeposition, therefore, offers viable solutions to the above-mentioned two problems of producing high-performance nickel-positive electrodes.

Electrodeposition of nickel hydroxide is carried out by the electrochemical reduction of an aqueous nickel nitrate solution. Nitrate reduction results in the electrogeneration of hydroxyl ions [11] according to the equation:

$\mathrm{NO}_{3}{ }^{-}+\mathrm{H}_{2} \mathrm{O}+2 \mathrm{e}^{-} \rightarrow \mathrm{NO}_{2}{ }^{-}+2 \mathrm{OH}^{-} \quad E^{0}=0.01 \mathrm{~V}$

The hydroxyl ions cause a steep increase in the $\mathrm{pH}$ close to the electrode surface and nickel hydroxide precipitation takes place, i.e.

$\mathrm{Ni}^{2+}+2 \mathrm{OH}^{-} \rightarrow \mathrm{Ni}(\mathrm{OH})_{2} \downarrow$

Despite the importance of this process, the electrochemical reduction of nitrate ions has not been investigated in detail in the context of nickel hydroxide electrosynthesis. By using linear sweep voltammetry, Fedurco and co-workers [12] have identified the features due to (i) nitrate reduction to nitrite and (ii) nitrite reduction to ammonia. The experiments were carried out on $\mathrm{NaNO}_{3}$ dissolved in $\mathrm{NaClO}_{4}$ as a supporting electrolyte using a silver working electrode. Although the reactions studied are the same as those 
involved in nickel hydroxide synthesis, the conditions employed are not relevant to the fabrication of nickelpositive electrodes. Further, $\mathrm{ClO}_{4}{ }^{-}$used as the supporting electrolyte is itself susceptible to electroreduction to $\mathrm{ClO}_{3}{ }^{-}$and other related species [13].

Weidner and co-workers [14-16] have studied the electrodeposition of nickel hydroxide by both experiment and theory. They observed a strong, anomalous dependence of the yield of nickel hydroxide on the electrolyte concentration. This dependence was attributed to the formation of a soluble, hydrolyzed species of $\mathrm{Ni}$ (II) at high $\mathrm{Ni}$ (II) concentrations in the bath. No attempt was made, however, to find direct evidence for nitrate reduction.

In the present investigation, the electrochemical reduction of nitrate ions that leads to hydroxyl ion generation, the consumption of the hydroxyl ions in a chemical reaction with resultant deposition of nickel hydroxide, and the subsequent redox reaction of nickel hydroxide are examined by means of cyclic voltammetry.

\section{Experimental}

Cyclic voltammograms were obtained with a Versastat Model II A (EG\&G PARC) scanning potentiostat driven by Model M270 electrochemistry software. Platinum foil (surface area, $3.75 \mathrm{~cm}^{2}$ ) was used as a working electrode and cylindrical platinum mesh (geometric area, $28 \mathrm{~cm}^{2}$ ) as the counter electrode. All potentials are measured with respect to a saturated calomel reference electrode (SCE). The scan was conducted between 0 and $-0.6 \mathrm{~V}$. It was then taken to $1.4 \mathrm{~V}$ and returned to $0 \mathrm{~V}$. Negative values of current correspond to anodic reactions.
Prior to cycling, the working electrode was degreased with detergent and rinsed in concentrated $\mathrm{HNO}_{3}$ and distilled water. It was then electrochemically cleaned by alternatively polarizing it anodically, cathodically and anodically in $1 \mathrm{M} \mathrm{KOH}\left(20 \mathrm{~mA} \mathrm{~cm}^{-2}, 30 \mathrm{~s}\right)$. Finally, the working electrode was polarized anodically in $1 \mathrm{M} \mathrm{HCl}(20 \mathrm{~mA}$ $\mathrm{cm}^{-2}, 30 \mathrm{~s}$ ) and washed in deionized water. It was then soaked in a nickel nitrate solution of the required concentration in an undivided cell for cyclic voltammetric studies.

Nickel hydroxide was also potentiostatically $(-0.65 \mathrm{~V})$ synthesized using a laboratory-built potentiostat. It was characterized by powder X-ray diffractometry (Jeol Model JDX8P Powder Diffractometer, Co $\mathrm{K} \alpha$ radiation, $\lambda=1.79 \AA$ ), IR spectroscopy (Nicolet Model Impact 400D FTIR Spectrometer, $\mathrm{KBr}$ pellets, $4 \mathrm{~cm}^{-1}$ resolution) and TG (laboratory built system, heating rate $5^{\circ} \mathrm{C} \mathrm{min}^{-1}$ ).

\section{Results and discussion}

The cyclic voltammogram of a platinum electrode in a $0.1 \mathrm{M}$ nickel nitrate solution is shown in Fig. 1. Two cathodic peaks $\left(\mathrm{C}_{1},-0.15 \mathrm{~V} ; \mathrm{C}_{2}, 0.60 \mathrm{~V}\right)$ and one anodic peak $\left(\mathrm{A}_{2}, 1.15 \mathrm{~V}\right)$ are observed. $\mathrm{C}_{1}$ is assigned to the nitrate reduction reaction and $\mathrm{A}_{2} / \mathrm{C}_{2}$ to the redox reaction of nickel hydroxide. The following observations support this assignment.

1. Nickel hydroxide is known to be an electrochromic material, which turns black on oxidation [17]. The film on the working electrode flashes to a black color at the potential corresponding to $\mathrm{A}_{2}$ and lightens in the negative-going scan at $\mathrm{C}_{2}$.

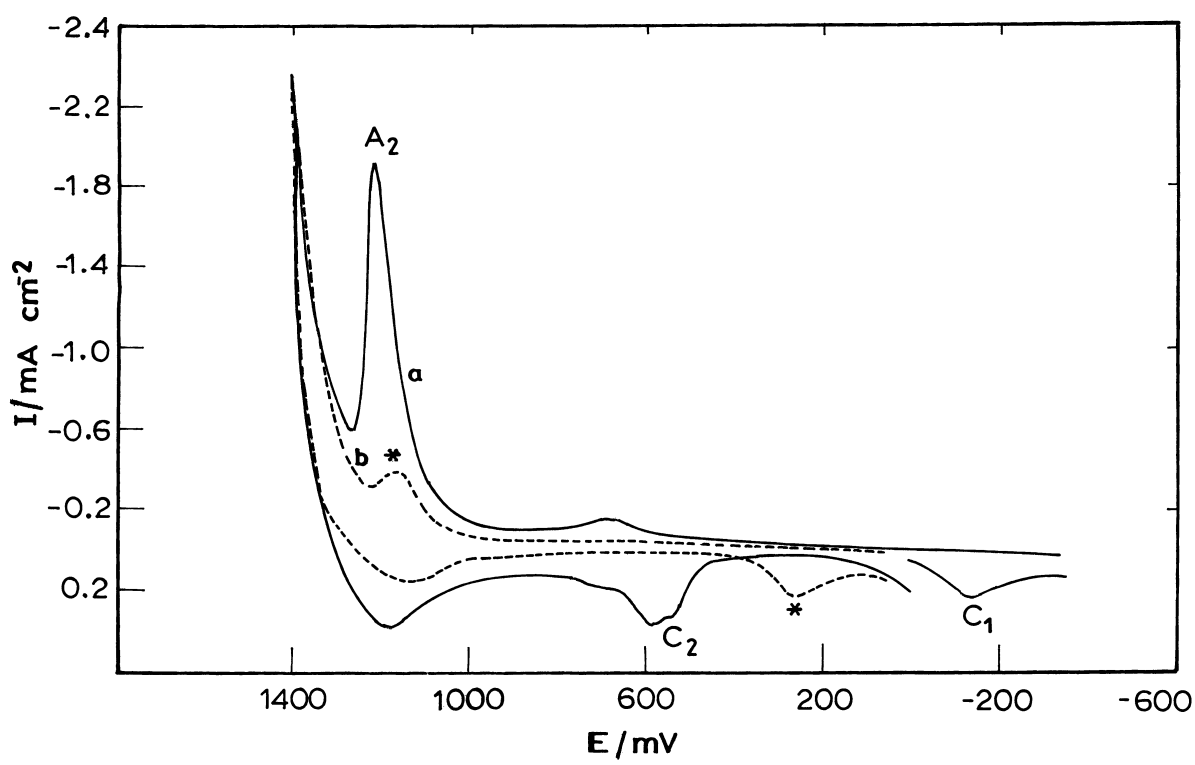

Fig. 1. Cyclic voltammogram for a platinum electrode in nickel nitrate solution $(0.1 \mathrm{M})$ recorded with switching potentials of $-0.35 \mathrm{~V}$ (curve a) and $0.05 \mathrm{~V}$ (curve b). The electrodes were held at the switching potential for $10 \mathrm{~min}$. Features marked by the asterisks correspond to the surface processes of a pure platinum electrode. 


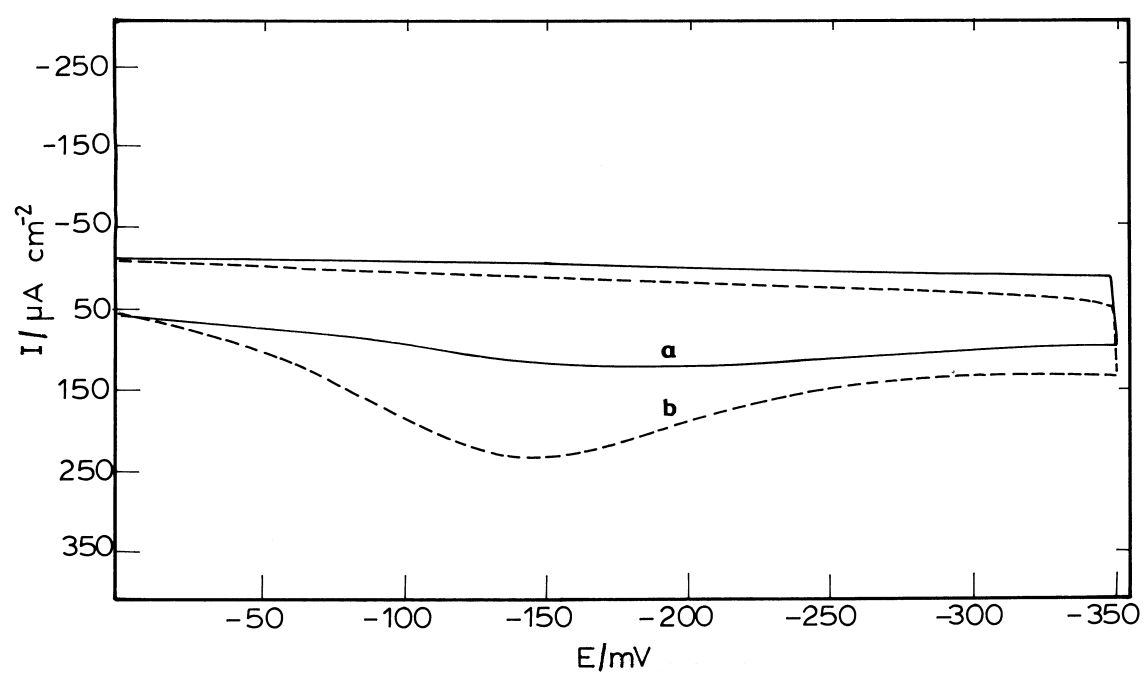

Fig. 2. Cyclic voltammograms in the region containing $C_{1}$ recorded in nickel chloride (curve a) and nickel nitrate (curve b) baths.

2. When $\mathrm{C}_{1}$ is eliminated by restricting the cathodic scan to a switching potential of $0.05 \mathrm{~V}, \mathrm{~A}_{2} / \mathrm{C}_{2}$ are not observed (see Fig. 1) and the working electrode does not turn black. This shows that no nickel hydroxide deposition has taken place.

3. To eliminate the effect of the hydrogen evolution reaction, which is also known to increase the $\mathrm{pH}$ [18], the negative switching potential was raised to $-0.35 \mathrm{~V}$. The cyclic voltammogram showed the presence of $\mathrm{A}_{2} /$ $\mathrm{C}_{2}$ and the working electrode turned black showing that nickel hydroxide deposition takes place at $\mathrm{C}_{1}$.

4. A potentiostatic synthesis performed at $-0.65 \mathrm{~V}(20 \mathrm{~h})$, which is a more negative potential than $\mathrm{C}_{1}$, yields an X-ray amorphous green powder, whose IR spectra and thermogravimetric data match with that of nickel hydroxide [1].
5. A cyclic voltammogram recorded in a nickel chloride bath does not exhibit any feature at $-0.15 \mathrm{~V}$, which shows that $\mathrm{C}_{1}$ is characteristic of the nitrate bath (see Fig. 2).

All these observations confirm that $C_{1}$ is responsible for nickel hydroxide deposition and therefore can be assigned to the nitrate reduction reaction.

\subsection{Nitrate reduction reaction}

Cyclic voltammograms recorded at different scan rates in the region containing $\mathrm{C}_{1}$ are presented in Fig. 3. The following features are observed.

1. The peak potential $\left(E_{\mathrm{p}}\right)$ of $\mathrm{C}_{1}$ shifts towards more negative potentials as the scan rate is increased. The

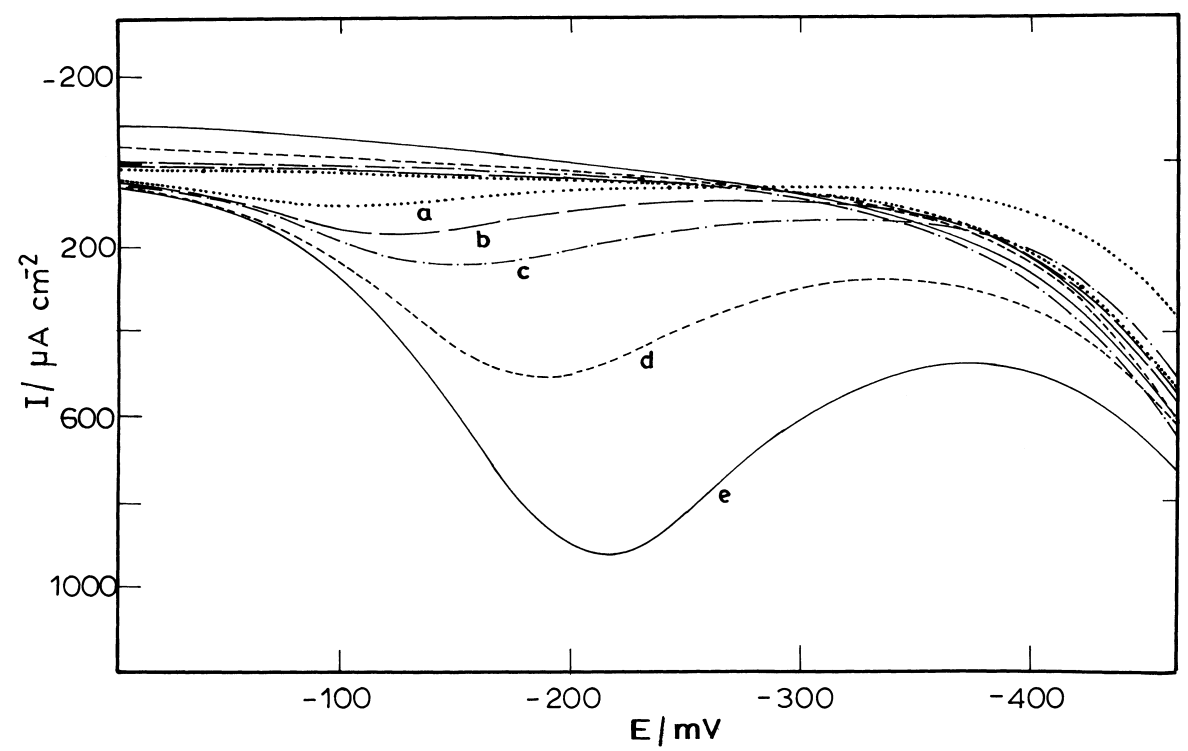

Fig. 3. Cyclic voltammograms for a platinum electrode in nickel nitrate solution at 5 (curve a), 10 (curve b), 20 (curve c), 50 (curve d) and $100 \mathrm{mV} \mathrm{s}^{-1}$ (curve e) scan rates. Only the region containing $\mathrm{C}_{1}$ is shown. 

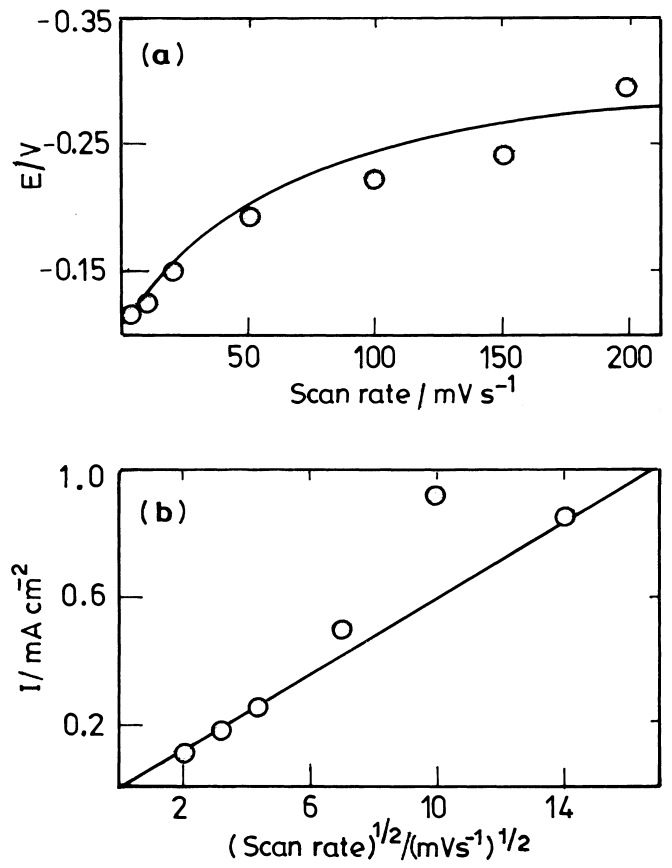

Fig. 4. Variation in (a) peak potential with scan rate and (b) peak current with (scan rate) ${ }^{1 / 2}$ for $\mathrm{C}_{1}$ due to the nitrate reduction reaction.

shift is significantly greater at low scan rates (Fig. 4a).

2. The peak current, $i_{\mathrm{p}}$, increases linearly with $v^{1 / 2}(v$, scan rate) (Fig. $4 \mathrm{~b})$. This suggests that the nitrate reduction reaction (NRR) is diffusion-controlled.

3. There is no peak which corresponds to $C_{1}$ in the positive-going scan. As the electrogenerated hydroxyl ions are consumed in the chemical precipitation of nickel hydroxide, the NRR is irreversible.
From these observations, it is evident that the NRR proceeds via an EC [19].

\subsection{Redox reaction of nickel hydroxide $\left(A_{2} / C_{2}\right)$}

The $\mathrm{A}_{2} / \mathrm{C}_{2}$ redox peaks at various scan rates are shown in Fig. 5. The following characteristics are observed.

1. The difference in anodic and cathodic peak potentials, $\Delta E_{\mathrm{p}}^{\mathrm{a}, \mathrm{c}}$, which is $0.42 \mathrm{~V}$ at low scan rates, increases with increase in scan rate (Fig. 6a).

2. The current function, $i_{\mathrm{p}} / v^{1 / 2}$, which corresponds to anodic peak $\mathrm{A}_{2}$, decreases with increase in scan rate, while that corresponding to $\mathrm{C}_{2}$ is independent of scan rate (Fig. 6b).

3. $i_{\mathrm{a}} / i_{\mathrm{c}}$ is always greater than 1 and increases with scan rate (Fig. 6c).

All these features are characteristic of a reversible redox reaction which follows an irreversible chemical reaction [19].

The reactions occurring at the working electrode can therefore be summarized as

$\mathrm{NO}_{3}{ }^{-}+\mathrm{H}_{2} \mathrm{O}+2 \mathrm{e}^{-} \rightarrow \mathrm{NO}_{2}{ }^{-}+2 \mathrm{OH}^{-}$Electrochemical, $\mathrm{C}_{1}$

$\mathrm{Ni}^{2+}+2 \mathrm{OH}^{-} \rightarrow \mathrm{Ni}(\mathrm{OH})_{2} \downarrow \quad$ Chemical

$\mathrm{Ni}(\mathrm{OH})_{2} \leftrightarrow \mathrm{NiO}(\mathrm{OH})+\mathrm{H}^{+}+\mathrm{e}^{-}$Electrochemical, $\mathrm{A}_{2} / \mathrm{C}_{2}$

An alternate possibility to the EC and CE (irreversible chemical reaction followed by a reversible electrochemical reaction) mechanisms proposed above is the disproportionation mechanism represented by

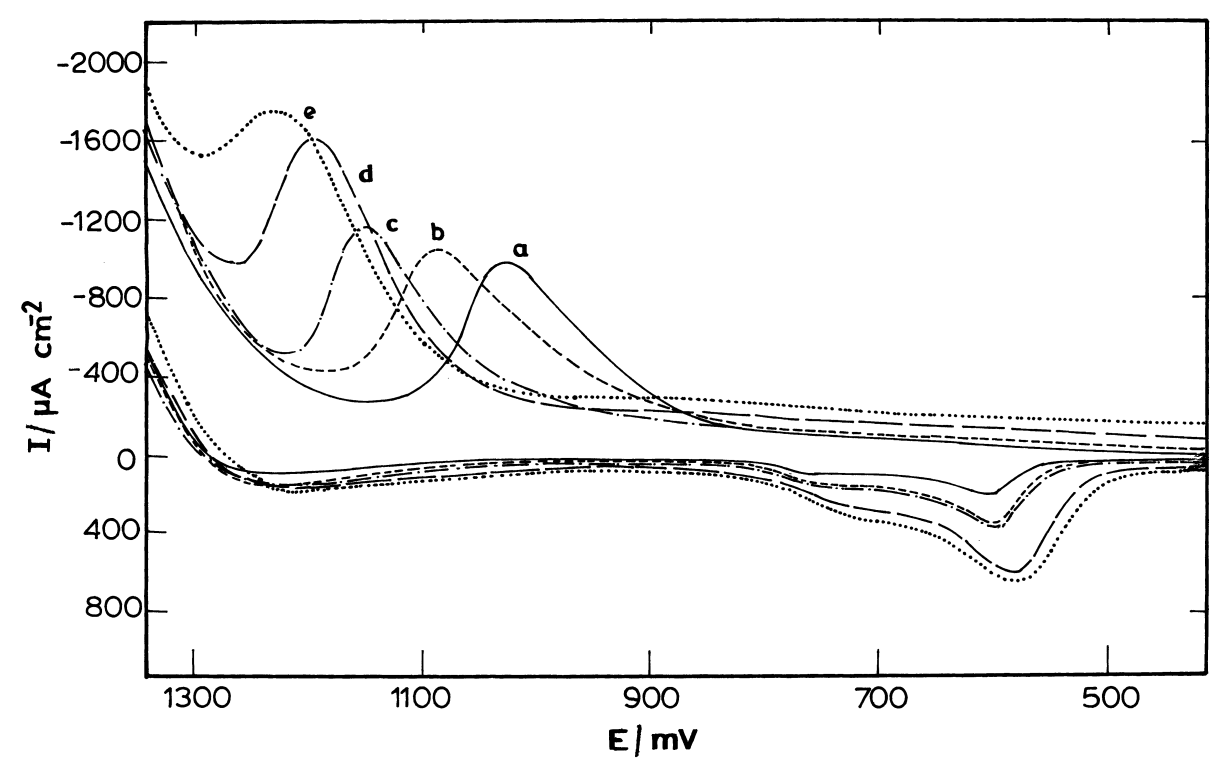

Fig. 5. Cyclic voltammograms for a platinum electrode in nickel nitrate solution at 5 (curve a), 10 (curve b), 20 (curve c), 50 (curve d) and $100 \mathrm{mV} \mathrm{s}^{-1}$ (curve e) scan rates. Only the region containing $\mathrm{A}_{2} / \mathrm{C}_{2}$ is shown. 

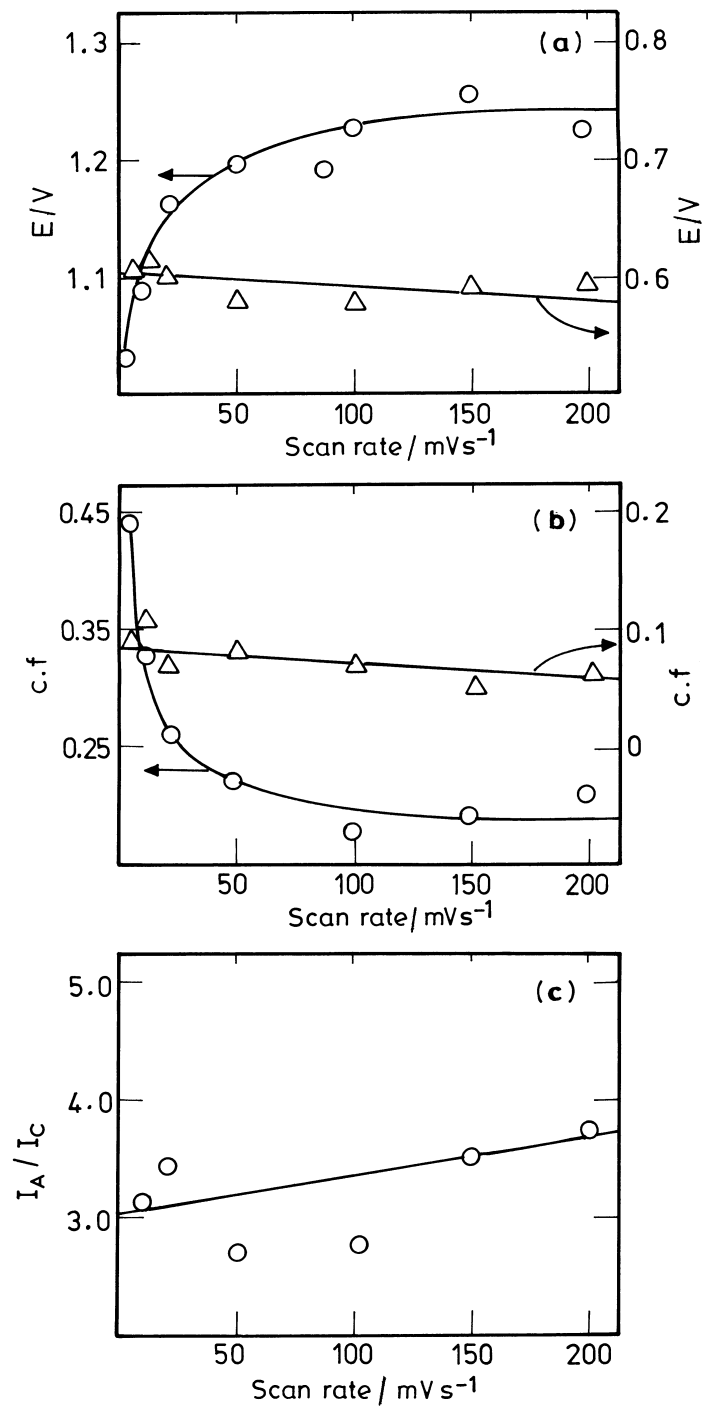

Fig. 6. Variation in (a) peak potentials, (b) current function (c.f.) and (c) ratio of anodic to cathodic peak currents as a function of scan rate. Open circles and open triangles correspond to $\mathrm{A}_{2}$ and $\mathrm{C}_{2}$, respectively, in (a) and (b).

$\mathrm{Ni}(\mathrm{OH})_{2}+\mathrm{OH}^{-} \leftrightarrow \mathrm{NiOOH}+\mathrm{H}_{2} \mathrm{O}+\mathrm{e}^{-}$

In this, the electrodeposition of nickel hydroxide and its simultaneous reaction with the electrogenerated base is envisaged. This would amount to the disproportionation of hydroxyl ions into water and an oxide ion. Disproportionation reactions are concentration dependent and the current function, $i_{\mathrm{p}} / v^{1 / 2}$, should increase with concentration for a given scan rate. In Fig. 7 are shown the plots of the current functions corresponding to $\mathrm{C}_{1}, \mathrm{~A}_{2}$ and $\mathrm{C}_{2}$ as a function of the $\mathrm{Ni}^{2+}$ concentration. The current functions decrease with increase in concentration. This suggests that the disproportionation mechanism is inappropriate in this context.

\section{Conclusions}

1. Deposition of nickel hydroxide in nickel nitrate baths follows the electroreduction of nitrate ions. Cyclic
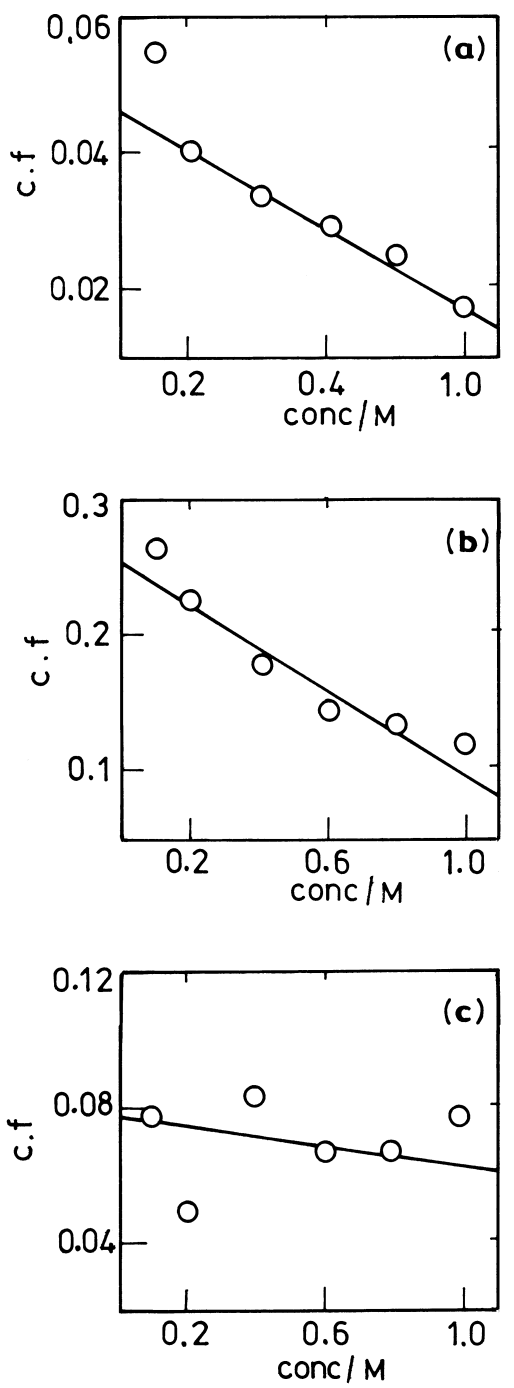

Fig. 7. Variation in current function (c.f.) of (a) $C_{1}$ (b) $A_{2}$ and (c) $C_{2}$ with bath concentration.

voltammetry studies show that this composite process proceeds via an EC mechanism.

2. The electrodeposited nickel hydroxide undergoes a subsequent redox reaction which is reversible.

\section{Acknowledgements}

PVK thanks the Department of Science and Technology, Government of India (GOI) for financial support. RSJ thanks the Council of Scientific and Industrial Research, GOI, for the award of a Senior Research Fellowship.

\section{References}

[1] P. Oliva, J. Leonardi, J.F. Laurent, C. Delmas, J.J. Braconnier, M. Figlarz, F. Fievet, J. Power Sources 8 (1982) 229.

[2] D.A. Corrigan, S.L. Knight, J. Electrochem. Soc. 136 (1989) 613. 
[3] M.C. Bernard, P. Bernard, M. Keddam, S. Senyarich, H. Takenouti, Electrochim. Acta 41 (1998) 91.

[4] R.S. Jayashree, P.V. Kamath, J. Appl. Electrochem. 29 (1999) 449.

[5] P.V. Kamath, M. Dixit, L. Indira, A.K. Shukla, V.G. Kumar, N. Munichandraiah, J. Electrochem. Soc. 141 (1994) 2956.

[6] M. Dixit, P.V. Kamath, J. Gopalakrishnan, J. Electrochem. Soc. 146 (1999) 79.

[7] M. Dixit, P.V. Kamath, V.G. Kumar, N. Munichandraiah, A.K. Shukla, J. Power Sources 63 (1996) 167.

[8] E.J. McHenry, Electrochem. Technol. 5 (1967) 275.

[9] K.C. Ho, J. Electrochem. Soc. 134 (1987) 52C.

[10] K.C. Ho, J. Jorne, J. Electrochem. Soc. 137 (1990) 149.

[11] J.A. Switzer, Am. Ceram. Soc. Bull. 66 (1987) 1521.
[12] M. Fedurco, P. Kedzierzawski, J. Augustynski, J. Electrochem. Soc. 146 (1999) 2569.

[13] D. Dobos, Electrochemical Data, Elsevier, New York, 1975.

[14] C.C. Streinz, A.P. Hartman, S. Motupally, J.W. Weidner, J. Electrochem. Soc. 142 (1995) 1084

[15] M. Murthy, G.S. Nagarajan, J.W. Weidner, J.W. Van Zee, J. Electrochem. Soc. 143 (1996) 2319.

[16] C.C. Streinz, S. Motupally, J.W. Weidner, J. Electrochem. Soc. 142 (1995) 4051.

[17] S.I. Cordoba-Torresi, C. Gabrielli, A.H. Goff, R. Toressi, J. Electrochem. Soc. 138 (1991) 1548.

[18] G.H.A. Therese, P.V. Kamath, J. Appl. Electrochem. 28 (1998) 539.

[19] R. Greef, R. Peat, L.M. Peter, D. Pletcher, J. Robinson, Instrumental Methods in Electrochemistry, Ellis Horwood, Chichester, 1985. 